\title{
ALTERNATIVAS JUVENIS
}

Marcos Antonio Batista da Silva-m.silva2009@bol.com.br Pontifícia Universidade Católica de São Paulo-PUC-SP-Faculdade Nossa CidadeCarapicuíba-SP.

RESUMO Neste artigo tratamos de jovens ligados a educação formal, especificamente, de estudantes, do terceiro ano do ensino médio, de escola pública de município da região metropolitana da Grande São Paulo, de ambos os sexos, na faixa etária entre 17 e 20 anos de idade, de camadas populares. Propomos um olhar sobre os jovens para além da educação formal, buscando compreendê-los como sujeitos sociais, que como tais, constroem uma determinada maneira de ser jovem. O estudo fez parte da pesquisa de mestrado em psicologia educacional onde se investigou a percepção do jovem sobre o trabalho. Trazemos, assim, elementos para o debate sobre a juventude, do que aspectos conclusivos, entre eles o papel da família na educação dos jovens, o que é ser joven numa sociedade globalizada e de consumo.

Palavras Chave: juventude, família, educação, mundo do trabalho.

\section{YOUTH ALTERNATIVES}

ABSTARACT In this article we deal with young people linked to formal education, specifically for students, the third year of high school, public school district of the metropolitan region of Greater São Paulo, of both sexes, aged between 17 and 20 years old of classes. We propose a look on young people to the formal education system, seeking to understand them as social subjects, which as such, build a certain way of being young. The study was part of the research master's degree in educational psychology where he investigated the perception of the young on the job. Thereby bringing elements to the debate on youth issues than conclusive, including the family's role in educating young people, which is to be young in a global society and consumption.

Key-words: youth, family, education, labor 


\section{Introdução}

Antes de situar meu objeto de pesquisa, acredito ser importante mencionar que o tema de interesse de estudo em si é consequência da minha trajetória, profissional, acadêmica e existencial. Em razão de ser afrodescendente tive precocemente um convívio com narrativas sobre questões relacionadas ao preconceito, e à intolerância. No Brasil é comum a afirmação de que no país não existem regras fixas ou modelos de descendência biológicas aceitas de forma consensual para definir o pertencimento racial da população (SOUZA, 2009 apud ROCHA; ROSEMBERG, 2007).

Tal fenômeno se assenta nas particularidades relacionadas ao modo como se deu a integração da população negra escravizada no país e da construção de narrativas acerca das especificidades da composição do povo brasileiro, engendrando modos particulares de identificação, assim como de manifestação do preconceito e do racismo. (SOUZA, p.30. 2009)

Desde muito jovem tive interesse em buscar formas de compreensão sobre as questões relacionadas à intolerância, ao preconceito e aos conflitos humanos. Contudo esta preocupação se tornou mais latente à medida que a minha trajetória de vida acadêmica se desenvolve. Percebi que grande parte destas questões estava associada às diferenças políticas, étnicas, sociais e econômicas. Refletir sobre tais questões me levou a estudar a juventude. Há fortes razões para estudar o atual contingente jovem brasileiro, em primeiro lugar: sua magnitude. Em 2007, segundo a Pesquisa Nacional por Amostra de Domicílios do Instituto Brasileiro de Geografia e Estatística (Pnad/IBGE), o Brasil possuía cerca de 50,2 milhões de jovens entre 15 e 29 anos, o que correspondia a $26,4 \%$ da população, embora esse contingente populacional fosse maior do que o das últimas décadas do século 20 (ANDRADE, 2008, p. 25).

Em segundo lugar, pela necessidade de se fazer uma reflexão sobre a educação de jovens. Neste sentido, quanto mais se articula o conhecimento frente ao mundo, mais os educandos se sentirão desafiados a buscar respostas, e, consequentemente, quanto mais incitados, mais serão levados a um estado de consciência crítica e transformadora frente à realidade. Essa relação dialética é cada vez mais assimilada na medida em que educadores e educandos se fazem sujeitos do seu processo. 
Em terceiro lugar, por estudar a juventude e alguns fatores que acontecem neste período. O tema juventude tem sido bastante discutido na sociedade contemporânea nos últimos anos, ampliando sua visibilidade e relevância, a exemplo do discurso inaugural da posse da atual Presidenta do Brasil, Dilma Rousseff, que abordou a questão social da juventude e suas implicações para um desenvolvimento de orientação democrática e popular.Acreditamos que trabalhar um projeto de vida com jovens faz com que o pesquisador revisite sua própria história, o que contribuiu para o estabelecimento de uma visão crítica sobre determinados aspectos relacionados a estas questões. Neste contexto, pensar sobre a cultura, a diversidade, a pluralidade nos leva ao pensamento de Dayrell (2003), no que se refere aos jovens como sujeitos sociais.

Geralmente, a noção de sujeito social é tomada com um sentido em si
mesma, sem a preocupação de defini-la, como se fosse consensual a
compreensão do seu significado. Outras vezes é tomada como
sinônimo de indivíduo, ou mesmo de ator social. Para alguns, falar em
"sujeito" implica uma condição que se alcança definindo-se alguns
pré-requisitos para tal; para outros, é uma condição ontológica,
própria do ser humano. (Dayrell, p.42, 2003)

Isto implica que o sujeito é um ser humano aberto a um mundo que possui uma historicidade, é portador de desejos, e é motivado por eles, além de estar em relação com outros seres humanos. Pertencente a uma determinada família, que ocupar um determinado lugar na sociedade. Charlot (2000). Nos limites deste artigo, que é um recorte da minha dissertação de mestrado em psicologia educacional que procurou conhecer a percepção de 50 jovens de escola publica do terceiro ano do ensino médio, de município de grande São Paulo sobre o trabalho, propomos discutir a juventude como uma construção social ,considerando, a influência dos espaços de socialização destes jovens vista a inserção laboral .

\section{Juventude uma construção social}

Tomando como principio que a categoria juventude é uma construção social, num contexto de diversidades socioculturais e dentro desta forma de perceber o jovem, procuramos situar elementos norteadores para o enfrentamento dos impasses próprios do mundo globalizado, como as novas dinâmicas de relação entre o homem e o trabalho, a educação formal e não-formal, a família e a própria juventude. Discutir a relação entre trabalho e jovens é mais do que analisar a questão de escolha de uma profissão e da obtenção de um emprego. Significa contribuir para a formulação de um projeto de vida, 
clivado de valores sobre o sentido do trabalho como meio de realização pessoal e de participação na transformação do mundo. Esta atitude inclui reflexões sobre a própria história de vida, com suas metas, desafios e sonhos.

$\mathrm{O}$ trabalho é também um meio de construção da identidade dos jovens. $\mathrm{O}$ melhor caminho para isso é, antes de tudo, dar voz ao sujeito do processo. A compreensão da juventude está circunscrita, de maneira integrada, nas relações sociais, culturais, políticas e econômicas, assim como no processo de formação da identidade. Quem trabalha com jovens pela perspectiva sócio-histórica pode perceber que ser jovem é ser um pouco polivalente, é estar conectado com varias coisas simultaneamente, sem estar, aparentemente, ligado a coisa alguma.

O jovem costuma se angustiar profundamente com as relações afetivas, com os vínculos dos relacionamentos grupais. Não existe uma maneira única de ser jovem. Cada um constrói, a sua maneira, um modo de ser, de agir, de confabular e de fazer sua história, dentro de uma circunstância dada. Se, de um lado, o jovem tem expectativas, de outro, as instituições, o mercado, a família e a sociedade também têm seus projetos. A dificuldade do jovem é integrar essas dimensões, uma vez que sua subjetividade se constrói e é construída no conjunto das relações sociais e de acordo com seu modo de assimilar e de responder às solicitações objetivas do cotidiano e da história.

A desigualdade social e as contínuas transformações no mercado de trabalho repercutem na vida e na formação do jovem. Essa realidade provoca o poder público, a sociedade e a família a discutirem a realidade do emprego, da capacitação profissional e da necessidade de políticas públicas voltadas à população juvenil. Tal procedimento compreende não apenas a formulação e a implementação de políticas de inserção, como também de programas socioculturais, capacitação profissional e para a cidadania, e a oferta de oportunidades de experiências de vida.

Na sociedade globalizada e de consumo, preparar para escolhas com princípios éticos, na idade das opções, é vital para o desenvolvimento humano. Em cada época da história, educadores, intelectuais e instituições têm-se preocupado com o processo e socialização e de profissionalização do jovem que, largado à deriva, poderia descambar para as práticas de violência. Nossa sociedade é marcada pela contradição. Se o trabalho é fonte de exploração, por outro lado, é também fonte de emancipação. A educação e a cultura tendem a ajudar o jovem a encontrar um sentido para o trabalho, que 
contribua para a construção de um sentido para sua vida. Numa sociedade marcada pela transitoriedade, repleta de sinais confusos, propensa a mudar com rapidez e de forma imprevisível e com um diagnóstico dominante apontando para as dificuldades de aproveitar oportunidades, especialmente em obter o primeiro emprego, em função do despreparo e da desqualificação frente à competitividade. Essa realidade coloca em xeque a proposta pedagógica da política educacional e da forma de pensar e de agir das famílias. Contudo acreditamos que, a escola, a família e as demais instituições devem cuidar da formação ético-social e profissional, para que o jovem possa modificar sua biografia e a de seus companheiros.

Diante do exposto acreditamos que a ampliação de espaços de socialização de adolescentes e jovens podem contribuir para o seu desenvolvimento. Neste sentido evidencio a Pedagogia Social. Para Souza Neto (2009), diferentemente de outras pedagogias, que trabalham em cima do fracasso dos indivíduos, a Pedagogia Social busca trabalhar as potencialidades, os atributos, onde uma pessoa que vive nas ruas pode aprender e ter um saber tão fundamental quanto outras pessoas, desde que alguém a ajude a canalizar suas energias e suas potencialidades.

\footnotetext{
As demandas sócio-educacionais do mundo moderno criam a necessidade de se viabilizar a formação de profissionais da educação especializados para o atendimento às questões sócio-culturais tal como já ocorre em muitos países. As experiências nessa área sócio educacional que consolidam tendo como referência a prática, a educação escolar e poucos aportes teóricos de diferentes áreas, exigem que se avance no Brasil na discussão de um projeto nacional para a educação social.(Machado,p.99.2008)
}

Isto implica em pensar em alternativas para reflexões e dados frente à importância de uma educação voltada para a autonomia, a cidadania e o cuidado de si e do outro: bases para a formulação de políticas públicas integradas para a prevenção e redução da vulnerabilidade social e existencial. Nesse sentido, a função social do educador é ser agente de transformação; cabe a ele auxiliar na organização dos desejos e necessidades da população com a qual trabalha. É importante identificarmos de que forma a compreensão dos fenômenos conhecidos como ritos de passagem podem ser úteis na realização de trabalhos de orientação profissional e vice-versa. Acreditamos que uma sociedade tão carente de simbolismos formais dessa ordem, como a nossa, acaba 
criando, por meio dos recursos disponíveis, outras formas de cristalizar seus aspectos mais subjetivos, tão necessários para o desenvolvimento do sujeito.

É importante lembrar que, muitas vezes, os jovens, hoje desempregados, são os trabalhadores infantis de anos atrás. Dessa forma, o aumento das oportunidades de trabalho decente para jovens não pode ser dissociado dos esforços de erradicação do trabalho infantil e da melhoria de perspectivas de emprego para adultos. Além do mais, o problema do desemprego de jovens reflete e perpetua déficits de trabalho decente nas famílias e comunidades.

Diante do exposto acreditamos que este tema social vem ganhando cada vez mais atenção à medida que crescem as desigualdades sociais e a concentração díspar de renda. A sociedade diante deste panorama, cobra maior envolvimento de todos os setores públicos e privados, no sentido de viabilizarem ações que permitam a inclusão social pelo desenvolvimento de potencialidades, pela melhora da Educação que possam dar condições dignas de vida e levantar a auto-estima dessa população crescente de excluídos. Dentre os setores sociais que podem contribuir para a inclusão social, gerando desenvolvimento econômico e social de uma nação ,destaca-se a escola e outros espaços de socialização como a família,e as organizações não governamentais.

É sabido que muitos adolescentes e jovens, em geral habitantes das regiões periféricas da grande São Paulo, em que na sua grande maioria do sexo masculino, abandonam a escola porque têm de trabalhar, com baixo índice de escolaridade. A falta da educação escolar tem como conseqüência a não profissionalização, gerando emprego informal, e estudos têm revelado que esse fator pode ser a causa de desigualdade e exclusão social que determina comportamentos de violência daqueles que se sentem privados de um bem que lhes é de direito.

Contudo, a ideia do pressuposto de que o jovem escolhe uma profissão a partir das condições em que vive da influência da família e em função de suas habilidades e aptidões não é uma ideia que sempre existiu; é algo que teve início quando se instalou na sociedade o modelo do capitalismo. E neste momento coloca-se uma questão: se tudo está na mão do sujeito, o momento de sua escolha profissional torna-se muito importante. Esse é um momento de conflito, e não devemos imaginar que o futuro de uma pessoa dependerá principalmente de sua opção profissional e que essa escolha não 
poderá ser alterada, principalmente devido a inúmeras influências que interferem nesse processo.

Entre eles podemos mencionar as características da profissão, o mercado de trabalho, a importância social da profissão, o histórico pessoal, a satisfação pessoal, a satisfação material, a vocação e o dom, a remuneração, as habilidades necessárias para o desempenho da profissão, a trajetória para se chegar a esse processo de escolha profissional, como: a escolarização, o vestibular, os custos da formação.

Outros fatores que merecem destaques aqui são os grupos sociais, e entre eles está a família e o grupo de amigos, de onde se espera que venham as principais pressões nesse processo de escolha. Não podemos aqui deixar de fazer menção às profissões ditas ocultas, muito comuns nos centros urbanos, como catadores de produtos para reciclagem, limpadores de vidros de carro em semáforos entre outras, que são originarias do sistema atual capitalista, seja por falta de escolarização, família ou políticas públicas. Para Bock "o indivíduo é escolhido para uma profissão pelas influências dos fatores sociais, da estrutura de classes, dos meios de comunicação e, de certa forma, da herança social" (BOCK, 1999, p. 248). Considerando que esse pensamento esteja correto, ao negar a possibilidade de liberdade de escolha, acabamos também percebendo esse indivíduo como reflexo da organização social, sem autonomia frente a essas determinações.

\section{Juventude, conflitos e modernidade}

$\mathrm{O}$ interesse pela juventude desponta de tempos em tempos. As crises e os excessos, os conflitos e as explosões que a eles se seguem, acompanham a história da preocupação social e acadêmica com a juventude.

[...] a tematização e uma maior visibilidade da juventude se constroem através do surgimento de um comportamento "anormal" por parte de grupos de jovens delinquentes, ou excêntricos, ou contestadores, implicando todos, embora de formas diferentes, em um contraste com os padrões vigentes. (ABRAMO, 1994, p. 8)

Podemos evidenciar o Movimento Juvenil Alemão, desencadeado por jovens estudantes no século 19, como forma de articulação de um novo estilo de vida, longe dos valores instituídos pelas gerações precedentes, com o objetivo de fundar uma nova 
sociedade, que iria romper a unidade da vida em nome do direito dos jovens de serem autônomos, porém seria necessário "declarar guerra" a outras formas da vida adulta. Contudo, outras questões, ou expressões, aconteceram para compor o desenvolvimento público da juventude.

Os anos de 1920 presenciaram a explosão desse interesse na razão direta da comoção gerada pela turbulência social em Chicago, nos Estados Unidos. Naquela época, toda uma geração de jovens tornou-se objeto de estudos da sociologia, em busca de uma resposta às indagações acerca de possíveis implicações entre juventude, violência, criminalidade e desorganização social urbana, atribuídas as contraposições aos padrões dominantes, que suscitam o tema do desvio no processo de integração dos jovens à vida social. As questões da delinquência, da rebeldia e da revolta, serviram de construção da problematização da questão da juventude ao longo deste século.

Outra experiência que podemos destacar foi a da participação traumatizante dos jovens europeus durante a Primeira Guerra Mundial, com muitas mortes e sofrimento. Nos anos de 1950, pela explosão demográfica nas urbes, e mais recentemente pelos elevados índices de disseminação das doenças sexualmente transmissíveis, as ciências humanas privilegiaram o exame da juventude sob a ótica do negativismo. Os excessos juvenis, tomados como impulso da desordem urbana, colocaram em movimento esforços de disciplinarização; associadas aos comportamentos disfuncionais, as pulsões da juventude tornaram-se foco da assepsia social, que queria o controle e a correção dos vícios, e nesse percurso as ciências reforçaram ao longo dos anos a percepção de que boa parte das mazelas sociais poderia ser creditada na conta da juventude e de seus anseios de diferenciação.

Firmou-se no imaginário social a associação entre a juventude e as grandes questões de cada tempo: no século 21, quando emergem as preocupações com o individualismo exacerbado e a criminalidade crescente, o jovem emerge como individualista e responsável, em grande parte, pela criminalidade urbana. Entretanto, na sociedade contemporânea, a ideia de violência não está mais associada somente às classes populares, de jovens das periferias dos grandes centros que não conseguiam se inserir na sociedade, mas também se estende à classe média, com características básicas de violência e exercícios de crueldade. O fenômeno do jovem novo, que se abriu da difusão de agressões a mendigos de rua, mulheres e homossexuais, entre outros, 
caracteriza a intolerância às diferenças sociais. Simbolizando a perda de prestígio social, eles se tornaram objetos de ataque desses jovens que, no fundo, temem o que possam a vir a ser, principalmente aqueles que ainda não encontraram um sentido para suas vidas.

Muitos jovens que construíram uma violência subjetiva de culto ao corpo cultivam músculos, representação da força, da beleza e do erotismo, mostram o desamparo e o desalento. À medida que eles ganham músculos, usam a violência, como um animal acuado que tenta manter o seu território. Esta é uma juventude acuada, com menos liberdade do que em épocas passadas, controlada, vigiada, seja pelo poder policial, seja em shoppings ou condomínios de classe média, o que nos faz refletir sobre os mais de 50 milhões de jovens da América Latina fora do mercado de trabalho, desvalidos e não reconhecidos socialmente.

Esses conflitos carregam a possibilidade de ruptura do processo de integração do jovem à ordem, da transmissão da herança cultural ou mesmo da própria ordem social. [...] antes de tudo, a condição de transitoriedade: a juventude é entendida como uma etapa de transição, que processa a passagem de uma condição social recolhida e dependente a uma outra mais ampla; um período de preparação para o ingresso na vida social adulta. (ABRAMO,1994, p. 11-14)

Existe uma convicção generalizada de que é necessário desenvolver programas e ações que melhorem a situação atual, levando-se em conta o aumento da vulnerabilidade desse grupo social, a limitada oferta de oportunidades e as especificidades da condição juvenil contemporânea. Ao longo da história há grande variedade de caracterizações e atribuições de sentido para essas crises da juventude. Para Sposito (2003), a moderna concepção de juventude derivou de longas transformações a partir do século 18, mas, com o advento da Segunda Guerra Mundial, incidiu sobre alguns aspectos, como o alongamento do período de transição entre a infância e a idade adulta e o retardamento da juventude para a inserção no mundo do trabalho.

Esse panorama nos remete à questão do trabalho que é uma das grandes preocupações da juventude atual e também o é no campo das políticas públicas para a juventude. Para Andrade (2008), a inserção do jovem no mercado de trabalho, tem sido marcada pelo signo da incerteza, porque ele tendem a ocupar as ofertas de emprego que surgem, quase sempre de curta duração e baixa remuneração, o que implica em pouca 
possibilidade de iniciar ou progredir na carreira profissional. Pesquisas nacionais ${ }^{1}$ têm mostrado que o trabalho está entre os principais assuntos que mais mobilizam o interesse dos jovens. No Brasil, navegamos, com todas as dificuldades e desigualdades, num mar mais pacífico, apesar da violência, pois aqui ainda existem possibilidades de oportunidades e de ascensão social. O futuro da juventude brasileira não é de declínio. É de esperança. (Suplicy, 2011).

\section{Família, espaço de proteção e socialização de jovens}

Encontramos na nossa literatura vários autores que acreditam que a família é um forte espaço de socialização que tem influências significativas entre seus membros. [...] A família, entendida como o primeiro contexto de socialização, exerce, indubitavelmente, enorme influência sobre a criança e o adolescente (REGO, 2002, p. 55). Para Vygotsky (1988), é no ambiente familiar que a criança inicia o seu processo de aprendizagem e, ao considerar a aprendizagem como profundamente social, afirma que, quando os pais ajudam e orientam a criança desde o início de sua vida, dão a ela uma atenção social mediada, e assim desenvolvem um tipo de atenção voluntária e mais independente, que ela utilizará na classificação e organização de seu ambiente.

Entendemos que a temática da família é vital para a organização da sociedade, bem como para o desenvolvimento das formas de sociabilidade dos jovens. Na adolescência, os espaços onde são possíveis as interações sociais se expandem. Consequentemente debilita-se muitas vezes a força do referencial familiar, caso este não esteja suficientemente bom para se opor ao novo grupo.Essa emancipação, durante esse processo de aquisição de autonomia pessoal como elemento constituinte, é um traço destacado na nova situação social do adolescente, o que nos faz compartilhar o pensamento de Minuchin (1982), que nos revela que a família sempre tem passado por mudanças que correspondem às mudanças da sociedade e que assume ou renuncia a funções de proteção e socialização de seus membros em resposta às necessidades da cultura, atendendo basicamente a dois objetivos: a proteção psicossocial de seus membros e a acomodação a uma cultura e à transmissão dessa cultura.

\footnotetext{
1 “Juventude Brasileira e Democracia: participação, esferas e políticas públicas", coordenada pelo Instituto Brasileiro de Análises Sociais e Econômicas (Ibase) e pelo Instituto de Estudos, Formação e Assessoria em Políticas Sociais (Pólis), em 2005; e "Retratos da Juventude Brasileira", coordenada por Abramo e Branco (2005).
} 
Este momento também está vinculado proximamente a outros processos de evolução na vida dos jovens, a exemplo do processo da identidade, "[...] com complexa e em permanente redefinição, segundo a multiplicidade de experiências e jogos relacionais dos quais o sujeito participa" (CARRANO, 2000, p. 18), que na realidade dos indivíduos produzem-se de maneira conjunta e, em geral, de maneira integrada. Neste sentido a influência familiar no desenvolvimento dos jovens é indizível, uma vez que a partir dela ele adquire os seus primeiros conceitos, que formarão, ao longo do tempo, os alicerces de seu caráter, servindo de orientação para os inúmeros caminhos que a vida imporá durante sua trajetória. Acreditamos que a família tem papel fundamental neste processo a partir de diferentes mecanismos, como recompensas, castigos, observações, imitações.

Entretanto, a família não tem um poder absoluto, porque "nem os pais poderão "talhar" em seus filhos as características cognitivas, sociais e de personalidade que rigidamente e a priori desejem" (MORENO e CUBERO 1995, p.190). Isso implica que deverão ser consideradas também, ao longo deste desenvolvimento, as experiências positivas e negativas vividas no interior da família.

\section{Contribuição Famíliar}

Quando pensamos hoje o conceito de família, é comum imaginá-la como se sempre tivesse existido na forma monogâmica e perfeita. Entretanto a família é uma instituição historicamente constituída que, ao longo do tempo, sofre modificações em função das transformações econômicas, culturais e sociais, o que provoca também a produção de diferentes subjetividades; nesse sentido, tais manifestações repercutem também na formação do jovem adolescente.

Elaborar um quadro completo da origem da família, portanto, é tarefa extremamente difícil e complexa. Compreender as concepções de família na atualidade requer que se resgate a historicidade das formas de organização familiar. Na literatura há um grande número de estudos respeitáveis que mostram que a família passou por transformações consideráveis, evoluindo junto com o homem e foi, ao contrário do que se pensava, resultado de um longo processo. Canevacci (1976) nos revela que os laços familiares permanentes são condicionados pela cultura, e não por necessidades biológicas. A família não é, portanto, algo biológico, algo natural ou dado, mas produto de diferentes formas históricas de organização entre os humanos. 
[...] a ideia de família foi o resultado de uma evolução, através de estágios sucessivos de desenvolvimento, dos quais a família monogâmica constituiu a última forma [...] cada uma dessas famílias teve uma longa vida nas tribos da humanidade, com períodos de infância, de maturidade e de decadência. (MORGAN in CANEVACI, 1976, p. 56-61)

Ao examinarmos a trajetória da família ao longo dos tempos, encontramos o antigo regime da aristocracia europeia, onde havia as casas grandes que consistiam em agrupamentos de 40 a mais de pessoas, inclusive não consanguíneos e agregados, e pautavam-se por excessiva hierarquia com nenhuma privacidade; os bebês nobres eram amamentados por amas-de-leite formando seus primeiros vínculos com alguém que não pertencia à família.

Já a estrutura da família camponesa se diferenciava da aristocrática, em que a autoridade social não estava investida "na figura paterna, mas na própria aldeia. Esta estrutura familiar comportava poucos filhos, que usualmente eram enviados, por volta de 6 a 10 anos, para a casa de outro camponês para um período de aprendizagem; aprendiam a depender da aldeia e não dos pais. A amamentação era realizada pela mãe com escasso envolvimento emocional, como uma tarefa incomodativa e consumidora de tempo. É importante observar que tanto na família camponesa como na aristocrática o treino de hábitos higiênicos eram pouco fiscalizados e o controle da vida sexual na fase genital era também superficial.

No Brasil, identificamos a passagem do modelo patriarcal feudal ao modelo patriarcal nuclear burguês. A história da instituição familiar, no Brasil, tem como ponto de partida o modelo patriarcal, importado pela colonização e adaptado às condições sociais do Brasil de então, latifundiário e escravagista. O patriarca era o detentor das posses, não apenas de seu latifúndio, mas de sua família, de seus agregados e escravos. Nessa configuração, a mulher era considerada propriedade do patriarca. Mercadoria cambiável nos casamentos arranjados, depois de casada, cabia à mulher administrar a casa e servir ao marido como reprodutora.

Com o advento da revolução industrial, pode-se falar em uma estrutura familiar característica da classe trabalhadora, em que todos os componentes deveriam trabalhar para garantir o sustento, sujeitando-se a extensos horários de trabalho e, em muitos casos, tendo a mulher alçada ao mercado de trabalho, assumindo frequentemente o papel de sustentáculo da família. Singly (2007) apreende a família como um espaço no 
qual os indivíduos acreditam proteger a sua individualidade, ao mesmo tempo em que sofrem intervenção do Estado mediante o apoio e a regulação sobre as relações dos seus componentes. Entende que ao longo das últimas décadas a discussão sobre a crise da família, no Ocidente, foi propiciada pelos efeitos do divórcio, pelo enfraquecimento da instituição do casamento e da baixa taxa de nascimentos.

Esses acontecimentos tanto indicaram a compreensão de que se delineara o enfraquecimento da família, quanto sugeriram a análise do surgimento de novos modelos familiares, caracterizados, por sua vez, pelas mudanças nas relações entre os sexos e as gerações, tais como: controle mais intenso da natalidade, autonomia relativa da sexualidade, inserção da mulher no mercado de trabalho, entre outras.

Ao acompanharmos as transformações no âmbito da família moderna, focalizando os comportamentos interpessoais, entendemos, pela visão do autor, que nas sociedades contemporâneas ocidentais os indivíduos não se parecem com aqueles das gerações precedentes, devido ao surgimento do indivíduo original e autônomo, resultante da imposição dessas sociedades, as quais fazem vigorar razões tanto ideológicas quanto objetivas.

Para Singly (2007, p. 54), [...] as famílias são dependentes da sociedade na medida em que devem atuar em um jogo cujas regras e o desenrolar das partes lhes são parcialmente desconhecidos." Isso implica que, sob essa visão, a família contemporânea é relacional, é privada e pública, é individualista e precisa de horizonte intergeracional. Entretanto é amplamente reconhecida a importância da família ${ }^{2}$ no cuidado e no bemestar de seus integrantes, uma vez que é ela o âmbito privilegiado e o primeiro a proporcionar a garantia de sua sobrevivência, o aporte afetivo fundamental para seu pleno desenvolvimento e para a sua saúde integral, absorção de valores éticos e de conduta, e a sua introdução na cultura e na sociedade em que estão inseridas. Essa importância adquire contornos ainda mais decisivos no caso dos indivíduos mais vulneráveis, como por exemplo, as crianças, os adolescentes e jovens, os idosos e os doentes.

\footnotetext{
${ }^{2}$ De acordo com o Estatuto da Criança e do Adolescente - ECA (1990) art. 25: "Entende-se por família natural a comunidade formada pelos pais ou qualquer deles e seus descendentes".Art. 4": "É dever da família, da comunidade, da sociedade em geral e do Poder Público assegurar, com absoluta prioridade, a efetivação dos direitos referentes à vida, à saúde, à alimentação, à educação, ao esporte, ao lazer, à profissionalização, à cultura, ao respeito, à liberdade e à convivência familiar e comunitária".
} 
Nessa perspectiva, por iniciativa do Estado e a sociedade elaboraram-se documentos a fim de estabelecer políticas públicas que visam atender a família, a exemplo do Plano Nacional de Promoção, Proteção e Defesa dos Direitos de Crianças e Adolescentes à Convivência Familiar e Comunitária, ${ }^{3}$ que estabelecem conceitos sobre a família e descrevem o marco situacional e as perspectivas das Políticas Sociais voltadas a potencialização das famílias, onde são apontadas também perspectivas sobre uma noção de família ampliada para dar conta do desenvolvimento do adolescente.

Diante do exposto, abordamos aqui a questão do (CRAS) Centro de Referência da Assistência Social, que é uma unidade pública estatal descentralizada da política de assistência social, responsável pela organização e oferta de serviços da proteção básica do Sistema Único de Assistência Social - SUAS, nas áreas de vulnerabilidade e risco social dos municípios e Distrito Federal. Dada sua capilaridade nos territórios, caracteriza-se como a principal porta de entrada desse sistema social, ou seja, é uma unidade que possibilita o acesso de um grande número de famílias à rede de proteção social de Assistência Social. E esta compreende a família como um espaço contraditório, marcado por desigualdades e, até mesmo, violência.

Nessa direção, ao eleger-se a matricidade social ${ }^{4}$ como eixo do sistema social, a família é enfocada em seu contexto sociocultural e econômico, com composições distintas e dinâmicas próprias. Essa compreensão busca superar a concepção tradicional de família, o modelo padrão, a unidade homogênea idealizada e acompanhar a evolução do seu conceito, reconhecendo que existam arranjos distintos, em constante movimento e transformação. Contudo, as novas concepções de família na sociedade moderna, muitas vezes contribuem para uma educação deficitária dos filhos, porque ao mesmo tempo em que podem suprir necessidades materiais, muitas vezes, não conseguem desenvolver um processo afetivo e de aprendizagem. O crescente número de relações pouco duradouras tem tido consequências drásticas no que diz respeito à estrutura da

\footnotetext{
${ }^{3}$ Conselho Nacional dos Direitos da Criança e do Adolescente. Secretaria Especial dos Direitos Humanos - Brasília-DF. CONANDA, 2006, p. 47.

${ }^{4}$ A matricidade sociofamiliar se refere à centralidade da família como núcleo social fundamental para a efetividade de todas as ações e serviços da política de Assistência Social. E define a família como conjunto de pessoas unidas por laços consanguíneos, afetivos e ou de solidariedade, cuja sobrevivência e reprodução social pressupõem obrigações recíprocas e o compartilhamento de renda e ou dependência econômica.
} 
família. Atualmente, poucas são as famílias onde se encontra pai, mãe e filhos vivendo em harmonia sob o mesmo teto, o que gera certa desestrutura.

No entanto, alguns especialistas afirmam que esse termo deve ser revisto. Desestrutura familiar, por exemplo, não quer dizer, necessariamente, ausência de pai ou de mãe; ou modelo familiar alternativo. A desestrutura tem a ver com as condições mínimas de afeto e convivência dentro da família, o que pode ocorrer em qualquer modelo familiar. No caso específico da influência da família no desempenho escolar dos filhos, fatores relativos à vida extraescolar dos alunos impactam no aprendizado: o contexto familiar do qual a criança ou adolescente se origina, a escolaridade dos pais, a valorização que a família atribui à escolarização, a preocupação com a boa trajetória dos filhos, o acompanhamento dos estudos e a participação efetiva na vida escolar dos estudantes são elementos centrais para um aprendizado eficiente.

O fato de os pais estarem inseridos do mercado de trabalho, não terem escolaridade, serem pobres ou serem ricos, negros ou brancos, não os exime da responsabilidade pela criação dos filhos. Antes do trabalho, ou qualquer outra coisa, deve vir o direito à vida. Os pais retiram esse direito quando se ausentam e não participam do desenvolvimento dos filhos. Essa ausência pode ser preenchida por sentimentos de frustração e abandono.

A família é também, o primeiro "mundo" que habitamos, podendo nos parecer acolhedor ou hostil, e como tal, regras, costumes, linguagens. Na relação famíliaescola, podemos questionar em alguns momentos e nos perguntarmos: por que a família é tão mal vista? Os professores dão algumas pistas. Eles dizem que quem leciona faz também o papel de assistente social, a escola está no lugar da família, onde o professor não ensina apenas, mas ajuda o aluno a sobreviver. Isso ocorre muitas vezes porque os pais não desenvolvem o papel que sempre lhe coube: criar e cuidar bem dos filhos, orientá-los nos estudos e prepará-los para a vida.

\footnotetext{
“A educação (recebida na família, na escola e na sociedade de um modo geral) cumpre um papel primordial na constituição dos sujeitos. A atitude dos pais e suas práticas de criação e educação são aspectos que interferem no desenvolvimento individual e, conseqüentemente, influenciam o comportamento da criança na escola". (VYGOTSKY, 1984, p. 87)
} 
A influência do lar como hábitat da criança e da família, assim como a influência do meio social mais amplo, é muito grande, principalmente na primeira infância e na adolescência, e essas são fases críticas do desenvolvimento do ser humano, que sempre requerem um maior cuidado e atenção.

\section{Método: Conhecendo os jovens participantes}

Participaram deste estudo 50 jovens de ambos os sexos, com idade ${ }^{5}$ entre 17 e 20 anos, de camadas populares, ${ }^{6}$ estudantes do $3^{\circ}$ ano do Ensino Médio, em escola pública, no município da grande São Paulo, todos em busca do primeiro emprego. A pesquisa foi realizada na própria escola dos jovens participantes, seguindo os pressupostos éticos para a realização da pesquisa. Utilizamos questionários, entrevistas e a técnica de grupo focal. O desenvolvimento deste trabalho foi norteado pelo referencial teórico sócio histórico. Para este artigo privilegiamos uma discussão sobre alguns dados coletados com a escola dos participantes por ocasião da pesquisa, entre eles: rendimento escolar, e étnica, elementos estes que iremos evidenciar a seguir.

\section{Os participantes de pesquisa: uma discussão}

A partir dos dados fornecidos pela escola pesquisada sobre o rendimento dos alunos referentes ao período de 2004 a 2006, pudemos observar que em relação ao Ensino Médio, nosso objeto de estudo, no ano de 2004, 93\% dos alunos foram promovidos, com ( $5 \%)$ de retidos e $(2 \%)$ de evadidos. Já no ano de 2005, houve aprovação para (84\%), retenção para ( $8 \%$ ) e evasão de( $8 \%$ ). Contudo, no ano de 2006, verificou-se (93\%) de aprovação, com ( 4\%) de retenção, e outros( $3 \%$ ) de abandono. Observamos também que a maioria dos jovens que abandonam os estudos são do período noturno.

Diante deste quadro fornecido pela escola pesquisada, é importante mencionar que a maioria dos jovens que abandonam os estudos são do período noturno. Daí pode implicar que, na maioria das vezes, isso pode ser devido à inserção no mundo do trabalho ou por desvio juvenil, o que reforça o propósito deste estudo de pôr na pauta do debate juvenil a inserção laboral dos jovens e nos remetem a políticas públicas da juventude que atendam as necessidades dos jovens para conciliar trabalho e

\footnotetext{
${ }^{5}$ A faixa etária escolhida corresponde à idade média de alunos do $3^{\text {a }}$ ano do Ensino Médio e por já possuírem, em termos de legislação trabalhista, idade para inserção no mundo do trabalho.

${ }^{6}$ Camadas populares decorrentes da pobreza e privação - inclusive quanto às condições de habitabilidade, segurança alimentar trabalho e geração de renda.
} 
escolarização. Nas últimas décadas temos testemunhado profundas transformações sociais e culturais, afetam as rotinas produtivas ,educacionais e econômicas no mundo globalizado sociais. Este novo contexto produziu novas desigualdades sociais que exigem do campo das políticas públicas para juventude alternativas para o enfrentamento deste novo quadro de exclusão que afetam em muito os jovens.

Acreditamos que somente a escola não pode ser responsabilizada pela solução dos problemas sociais que afligem seus alunos, particularmente no que tange às dificuldades de conciliar a escola e o trabalho. Parece evidente a necessidade de desenvolver ações conjuntas entre as escolas, as famílias destes jovens e o próprio jovem para uma discussão em torno destas questões possibilitando ao jovem alternativas de escolarização, capacitação e inserção laboral, e que esta não atrapalhe o seu desenvolvimento educacional.

Dentro dessa forma de perceber o jovem, procuramos situar elementos norteadores para o enfrentamento dos impasses próprios do mundo globalizado, como as novas dinâmicas do trabalho, a educação, a família e a própria juventude. Na sociedade nos deparamos com uma série de imagens a respeito da juventude, que consequentemente interferem na nossa forma de perceber este jovem. Entre elas podemos mencionar a visão do jovem como problema, como rebelde ou até mesmo em uma visão romântica, estas questões como discute Dayrell (2003), nos remete pensar os jovens de maneira negativa através dessas imagens construídas, fechando em conceitos muitas vezes estereotipados que nos limitam a compreender os jovens enquanto sujeitos e um determinado modo de ser jovem, baseados em seu cotidiano. Acreditamos que não há uma única maneira de ser jovem.

\section{Considerações Finais}

Os participantes muitas vezes se referem à família como sendo mantenedores de papéis sociais conservadores, desejando que os jovens construam projetos de vida que correspondam a expectativas dos próprios pais, seja para responder à imagem sobre eles projetada da própria juventude ou em projetos de vida que visem o aumento de renda da família, sem considerar o desejo do próprio jovem. O que implica que a família pode tanto ajudar quanto dificultar o jovem no momento de suas escolhas, entre elas a 
profissional, no momento em que o jovem está construindo sua identidade tanto pessoal como vocacional.

Entendemos que a escola é um espaço que acolhe, e onde o jovem pode aprender, mas não basta apenas passar um volume grande de conteúdos: é preciso preparar para pensar. Deve ser um território em que o jovem possa exercitar suas vivências e convivências. É nesse espaço de convivência e aprendizagem, em que se dão encontros e relações, que o jovem questiona valores e começa a construir seu projeto de vida. Porém, muitos esforços ainda precisam ser construídos objetivando uma maior aproximação da escola com a vida cotidiana dos jovens.

Tendo isso em mente, foi importante conhecer os aspectos das percepções dos jovens do Ensino Médio de escola pública, por favorecer uma visão mais ampla do tema juventude e inserção laboral. A partir dessas reflexões e pressupostos podem-se atingir profissionais que trabalham com grupo de adolescentes, e que, ao longo de sua atuação, podem ser privilegiados com essa discussão. Entendemos que nessa convivência o trabalho com jovens se pauta na construção de vínculo que viabiliza a percepção das contradições pessoais e grupais. objetivando novos caminhos. Contudo, nos tempos atuais, no momento em que a sociedade exibe um cenário de crise de valores e ao mesmo tempo de transformações tecnológicas e sociais que repercutem na forma e na diversidade de modos do jovem participar socialmente e buscar uma inserção no mundo do trabalho, o presente estudo propicia uma reflexão necessária, no propósito de questionarmos também que jovem e que sociedade queremos formar.

Entretanto, para uma expressiva parcela dos jovens desta pesquisa, os caminhos para o mundo do trabalho são íngremes. Várias pesquisas sobre essa temática, a exemplo das realizadas por organizações internacionais como a Organização Internacional do Trabalho (OIT, 2008) nos revelam crescimento da população jovem. A partir dessa condição, pode-se dizer que há uma tendência de o mercado de trabalho não conseguir absorver toda essa demanda de jovens. Segundo o mesmo relatório, a condição do jovem é bem mais precária que a dos adultos, pois as chances de aqueles estarem desempregados são três vezes maiores do que as destes, tanto no cenário nacional como no internacional. 
Um dos motivos principais dos relatos dos jovens participantes desta pesquisa no que se refere à dificuldade de inserção no mercado de trabalho é a falta de experiência, uma característica forte que se pode atribuir também a este grupo. Entendemos que é nesta fase da juventude que o adolescente vai à busca do seu primeiro emprego. No entanto, ele se depara com uma nova organização produtiva no mundo do trabalho, originária dos impactos da competição, da tecnologização e da globalização na relação homem-trabalho, que estão marcadas por uma série de mudanças, de caráter estrutural, para os quais contribuem o enorme avanço do conhecimento científico e suas correspondentes inovações na área produtiva e globalizações do cenário mundial, que são inerentes ao capitalismo.

Falar sobre a percepção do jovem sobre o trabalho é considerar que, apesar de estarem inseridos em uma sociedade onde os jovens têm vivido uma crise no mercado de trabalho frente às novas dinâmicas do trabalho no mundo globalizado e em constante transformação, devido aos impactos causados pelas novas tecnologias e flexibilidade e individualização do trabalho, com desemprego e falta de capacitação adequada, os jovens valorizam o trabalho, seja como realização pessoal, como fonte de renda, como meio de liberdade, como contribuição social. Contudo um trabalho para a juventude supõe políticas públicas de inserção no mundo do trabalho, onde sejam priorizadas jornadas de trabalho compatíveis com as de estudos, e programas de capacitações. Pensar nessa questão é entender que essas ações não são apenas privilégios para os jovens, mas sim, ações que têm consequências sobre toda comunidade, beneficiando a escola e a família, melhorando a qualidade de vida nas cidades, diminuindo a violência e construindo projetos de vida.

\section{Referências Bibliográficas}

ABRAMO, H. W. Cenas juvenis: punks e darks no espetáculo urbano. São Paulo: Scritta, ANPOCS, 1994.

ANDRADE, C.C. Juventude e trabalho: alguns aspectos do cenário brasileiro contemporâneo. Mercado de Trabalho, SP: IPEA, n38, Nov.2008.

BOCK. Ana Mercês Bahia; FURTADO. Odair e TEIXEIRA, Maria de Lourdes Trassi. Psicologias: uma introdução ao estudo de psicologia. São Paulo: Saraiva, 1999. 
CANEVACCI, M. Dialética da família. 2a ed. São Paulo: Brasiliense, 1976.

CARRANO, P. C. R. (2000). Juventudes: as identidades são múltiplas. Rio de Janeiro: Movimento (Univ. Fluminense). (1), maio, p.11-27

CONANDA \& SEDH. Diretrizes Nacionais para a Política de Atenção Integral à Infância e à Adolescência. Brasília: 2002.

CONANDA e UNICEF. Sistema Nacional de Atendimento Socioeducativo - SINASE. Brasília: junho de 2006.

CONFERÊNCIA NACIONAL DOS DIREITOS DA CRIANCA E DO ADOLESCENTE. Anais da IV Conferência Nacional dos Direitos da Criança e do Adolescente, 19 a 22 de novembro de 2001. Brasília: CONANDA, 2002.

CONANDA. Pacto pela Paz. Propostas aprovadas na Plenária Final. IV Conferência Nacional dos Direitos da Criança e do adolescente, 2002. Disponível em http://www.mj.gov.br/sedh/ct/conanda/pacto2.htmT.

DAYRELL, Juarez. O jovem como sujeito social. Revista Brasileira de Educação. 2003. $\mathrm{n}^{\circ} .24$, p.40-51, set/out/nov/dez

IBGE. Pesquisa Nacional por Amostragem de Domicílios. Acesso em: 15 jan.2011, http://www.ibge.gov.br/home/estatistica/populacao/trabalhoerendimento/pnad2009/defa ult.shtm

MACHADO, Evelcy M.. A Pedagogia Social: Diálogos e Fronteiras como Educação Não-Formal e Educação Sócio Comunitária..Revista de Ciências da EducaçãoUNISAL - Americana/SP - Ano X - N..$^{\circ} 18$ - $1 .^{\circ}$ Semestre/2008.

MINUCHIN, Salvador. Famílias, funcionamento e tratamento. Porto Alegre: Artes Médicas, 1982.

MORENO, M. C. e CUBERO, R. () "Relações sociais nos anos pré-escolares em desenvolvimento psicológico e educação. In: COLL, Cesar et al. Desenvolvimento psicológico e educação: psicologia evolutiva. Vol. 1. Porto Alegre: Artmed, 1995, p.190-202.

MORGAN, Lewis. A família antiga. In: CANEVACCI, Massimo (org). Dialética da família: gênese, estrutura e dinâmica de uma instituição repressiva. Trad. Carlos Nelson Coutinho. São Paulo: Editora Brasiliense, 1976. 
OIT.Relatório sobre o mundo do trabalho 2008. Disponível em http://www.oitbrasil.org.br/content/relat\%C3\%B3rio-sobre-o-mundo-do-trabalho2008,Acesso em 05.set. 2011.

REGO, T. C. Configurações sociais e singularidades: o impacto da escola na constituição dos sujeitos. In: OLIVEIRA M. Kohl et al. Psicologia, educação e as temáticas da vida contemporânea. São Paulo: Moderna, 2002, p.47-76.

ROCHA, Edmar José da; ROSEMBERG, Fúlvia. Autodeclaração de cor e/ou raça entre escolares paulistanos(as). Cadernos de Pesquisa, São Paulo, v. 37, n. 132, p. 759-799, dezembro de 2007.

SINGLY, F. Sociologia da família contemporânea. Rio de Janeiro: FGV, 2007.

SOUZA, Raquel. Ser homem: percepções, significados e narrativas de rapazes negros e pobres da cidade de São Paulo Dissertação (Mestrado - Programa de Pós-Graduação em Educação. Área de Concentração: Sociologia da Educação - Faculdade de Educação da Universidade de São Paulo.-- São Paulo:.2009.

SOUZA, Raquel. Ser homem: percepções, significados e narrativas de rapazes negros e pobres da cidade de São Paulo Dissertação (Mestrado - Programa de Pós-Graduação em Educação. Área de Concentração: Sociologia da Educação - Faculdade de Educação da Universidade de São Paulo.-- São Paulo:.2009.

SPOSITO, Marilia Pontes. Espaços públicos e tempos juvenis. IN: SPOSITO, Marilia Pontes (Orgs.). Espaços públicos e tempos juvenis: um estudo de ações do poder público em cidades de regiões metropolitanas brasileiras. São Paulo: Global, 2007. p.545 .

SPOSITO,Marilia Pontes. Os jovens no Brasil: desigualdades multiplicadas e novas demandas políticas. São Paulo: Ação Educativa, 2003.

SUPLICY, MARTA. Juventude e rebelião. Disponível em: http://www1.folha.uol.com.br/colunas/martasuplicy/959089-juventude-erebeliao.shtml.Acesso em: 05 set 2011.

VYGOTSKY, L. S. O desenvolvimento psicológico na infância. São Paulo: Martins Fontes, 1998.

VYGOTSKY, L. S. A formação social da mente. São Paulo: Martins Fontes, $1984 / 1988$. 

do Campus Jatai - UFG 